\title{
Local Clay Mineral in Flame Retardant Finishing of Cotton Fabric
}

\author{
Faheem Uddin", Tanzeel Areeb, Amjid Hussain, Ayesha Nadeem \\ Department of Textile Engineering, FE, Baluchistan University of I. T. Engineering and Management Sciences, Pakistan \\ *Corresponding Author: dfudfuca@yahoo.ca
}

Copyright () 2015 Horizon Research Publishing All rights reserved.

\begin{abstract}
Recently, clay minerals particularly received significant interest in polymer and fiber finishing. Enhanced performance effects are achievable using clay mineral in polymeric material. However, special finishing of fibrous material requires studies for establishing any useful effect or for finish development. Fabric finishing using clay may introduce improved flame retardancy. The aim of this paper is to report the results obtained in the flame retardant cotton finishing using local clay minerals. The two types of local clay samples used in this study are described in terms of the flame retardant effects on bleached cotton fabric. It is an indigenous study of clay reserves of country to explore the effects of prepared clay in textile finishing. Effects of indigenous clay samples were collected and the finished cotton was studied in terms of ease of ignition, standard burning length, observed flame propagation, and the residue formation. The finished fabrics were assessed using vertical flame retardant tester.
\end{abstract}

Keywords Clay Mineral, Flame Retardancy, Cotton, Polymer

\section{Introduction}

Flame retardant finishing of cellulose, wool and synthetic fibers is desired in producing variety of textile articles (1). Flame retardancy can be imparted through chemical finishing of fibers or by incorporating the flame retardant in polymer structure (2).

Environment- friendly flame retardants received interest in meeting the stricter regulations (3-4). Therefore, the study of flame retardant effects produced by clay mineral can be interesting. Study of enhancing the properties of fibers using clay is recently emerging as an important subject. An increasing consumption of clays in polymer finishing was indicated (5). Variety of clay minerals was known; however, montmorillointe (MMT) type minerals received an increasing research interest. The opportunities possible in the utilization of clay in the fiber- forming polymers were described, and the possibility of using the clays in textile finishing was identified (6).

MMT clay as an additive with polyurethane resin coating for textile fabrics for improved flame retardancy was studied (7). Introduction of MMT as an additive for improving thermal stability or flame retardancy in fiber- forming polymers has been reported for polyamides 6 , and 6.6, polypropylene, and polyester (8-9).

The study of combustion process and flame retardancy of polyester fabric have utilized hydrotalcite, nanometric titania, and silica aqueous suspensions where only hydrotalcitecontaining finishing resulted in consistent enhancement in time to ignite, and flame retardancy levels (10).

Flame retardant coating comprising branched polyethylenimine (BPEI) and sodium MMT applied to cotton fabric via layer- by- layer assembly (11). Highest clay loading was obtained at 1 wt. \% MMT. Each recipe of coating applied was investigated at 5 and 20 bilayers. Interestingly, an increased char formation to $13 \%$ was obtained on heating to $500^{\circ} \mathrm{C}$. The amount of char obtained from coated cotton fabric was 2 orders of magnitude higher relative to bleached cotton fabric. Examination of post- burn fabric residue using SEM indicated the presentation of weave structure and fiber shape.

Burning was studied using vertical flammability test where reduced afterglow time was observed in clay- coated fabrics. Improved flame retardancy was achieved through

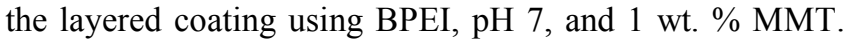
Total heat released and heat release capacity, assessed by micro combustion calorimeter test, was reduced in all coated fabrics.

Nanocomposite produced from cotton and montmorillonite showed enhanced thermal properties relative to unbleached cotton. The degradation temperature was increased by $45^{\circ} \mathrm{C}$, and char yields were possible to reach twice in amount relative to unbleached cotton (12).

Nylon 6/ organically modified MMT- based thin films, fibers and fabrics studied for condensed- phase flame retardancy (13). Results obtained indicated the horizontal flame spread on thin films produced no significant difference between burning behavior of nylon 6 and its nanocomposites 
with 5 wt. \% organically modified MMT (OMMT). Increasing its loading to $8-10 \mathrm{wt}$ \% produced nylon 6 burning without dripping, and flame spread reduced to 30 $40 \%$ with nylon 6 films. Undrawn nanocomposite monofilaments containing 10 wt. \% of OMMT burned slowly without dripping. Nanocomposite fabrics with 8 wt. \% loading of OMMT showed, relative to nylon 6 fabrics, a mass loss reduction of $40-60 \%$. The heat release rate was reduced, and fabric char retained weave structure.

The aim of this paper is to report the results obtained using local clay samples in flame retardant finishing of cotton fabric. It is an indigenous study of clay reserves of country to explore the effects of selected clay in flame retardant finishing of cotton fabric. Cotton fibers and clay mineral are natural materials. Therefore, flame retardant cotton fabric would be a natural composite material- free from the release of hazardous combustion products. The results obtained would be useful in enhancing the work in the development of local clay mineral based flame retardant finish for cotton fibrous material.

The two types of local clay samples used in this study are described in terms of the flame retardant effects on bleached cotton fabric. It is an indigenous study of clay reserves of country to explore the effects of prepared clay in textile finishing. Effects of indigenous clay samples were collected and the finished cotton was studied in terms of ease of ignition, standard burning length, observed flame propagation, and the residue formation. The finished fabrics were assessed using vertical flame retardant tester.

\section{Experimental}

\subsection{Materials and Chemicals}

\subsubsection{Clay mineral}

The natural clay samples received from the local sources were used in this study. These clay samples were collected from two different sources. The two types of local clay samples used in this study are described as Clay 3, and Clay 4:

Clay- 3: This clay was Fuller's earth (Jurassic clay), and locally called Multani matti. It consists of hydrated aluminium silicates that contain metal ions such as magnesium, sodium, calcium, with in their structure. Though it is similar in appearance to clay but it differs by being more fine grained and by having higher water content. It is found in a wide range of natural colors from brown or green to yellow or white.

Clay- 4: This clay was mainly kaolin collected from selected area (located adjacent to university (BUITEMS)). The sample was generated by digging one foot below the ground level.

\subsubsection{Fabric used}

Bleached plain woven cotton fabric, supplied by a local industry, was used as supplied. Its construction details include:

- Construction: $30 \times 30 / 76 \times 68$

- Fiber: $100 \%$ Cotton

- GSM: $115.66 \mathrm{~g} / \mathrm{m}^{2}$

Tap water was used in producing the aqueous dispersion of selected clays.

\subsection{Equipment}

Padder used was supplied by Guangzhou Hongjing Lab Equipment, Modeal: P-B1, Power: $0.5 \mathrm{KW}$.

Oven used for drying of padded fabric was R \& M Heating Drying Oven, Model: DHG 9023A.

Sieve used was supplied by Dual Manufacturing Co., U.S Standard Sieve ASTM E-11, Sieve No 200, 75 Microns.

Other equipment used includes exhaust heating bath, mortar, scissor, weighing balance, beakers, measuring cylinders, stirrers.

\subsubsection{Vertical flame retardant tester}

Vertical flame retardant tester used in this study was devised by the project team (Figure 1) using the specification provided by the BS EN ISO 69402004 for the assessment of ease of ignition (time taken by the mounted specimen in producing a self- sustained flame) indicated as $\mathrm{T} 1$, and measuring the time taken by the mounted specimen in reaching the flame to half of its length, indicated as T2, and time taken in burning of full length, indicated as T3. The size of each finished specimen tested was $(200 \mathrm{~mm} \pm 2 \mathrm{~mm}) \times$ $(80 \mathrm{~mm} \pm 2 \mathrm{~mm})$. Natural gas (commercial grade methane) was used for producing flame.

Important parts of the devised vertical flame retardant tester can be shown in Figure 2.

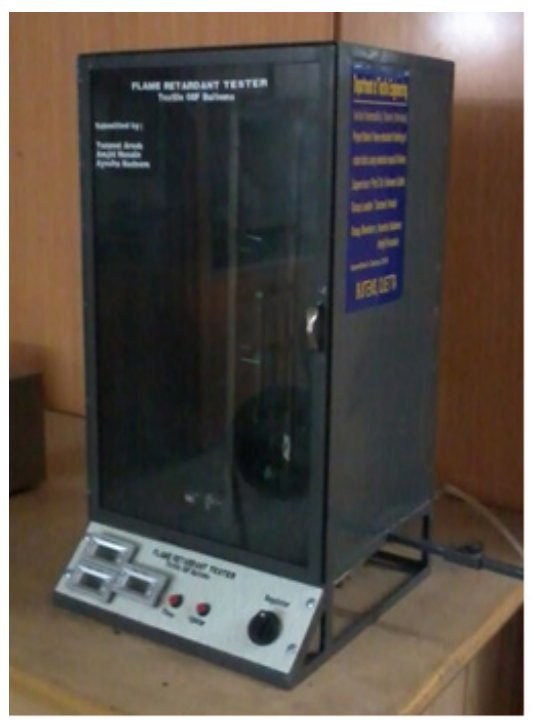

Figure 1. Vertical flame retardant tester produced using the specification of BS EN ISO 69402004. 


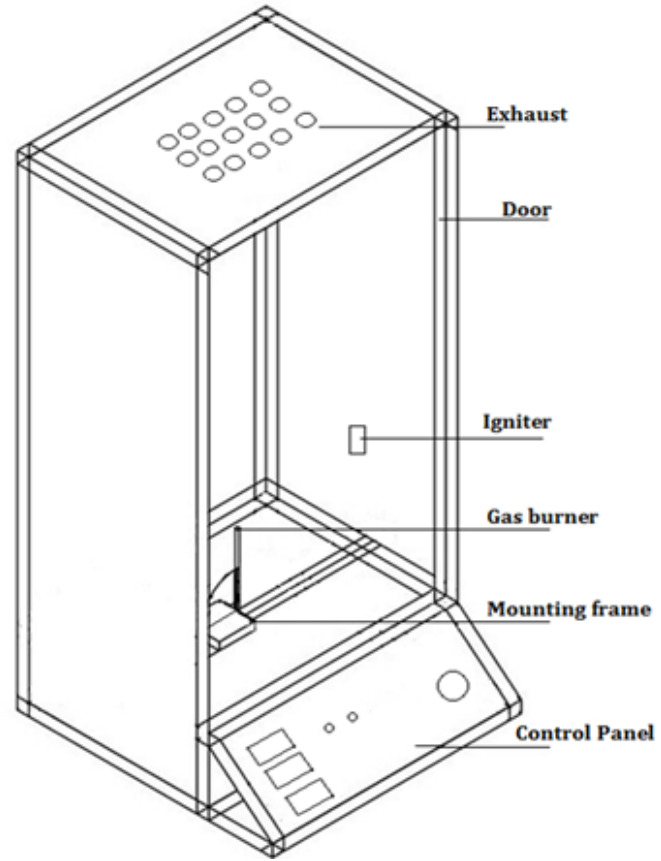

Figure 2. Important parts of devised vertical flame retardant tester using specification provided in specification of BS EN ISO 69402004.

\section{Methods}

\subsection{Grinding}

The clay sample received was in the form of larger aggregates of particles that was not appropriate applicable to fabric. Therefore, it was grinded in pestle until the particles were finely grinded prior sieving to achieve clay sample containing particle size of 75 micron.

The details of the grinding and grinding time, sieving and sieving time were variable for each clay type depending upon its physical form. However, in each case the aim was to obtained clay particle size of 75 micron.

Clay- 3: Weight of clay sample taken for grinding was $267 \mathrm{~g}$. It was required to grind and sieve for 8 times to achieve the desired particle size of 75 micron. Each time grinded for $15 \mathrm{~min}$ and sieved for $5 \mathrm{~min}$. After grinding and sieving it was again weighed. Weight of waste left after sieving was $133 \mathrm{~g}$. Weight of the desired sieved (75 micron) clay produced was $134 \mathrm{~g}$.

Clay- 4: Weight of clay sample taken for grinding was $300 \mathrm{~g}$. It was required to grind and sieve for 3 times to achieve the desired particle size of 75 micron. Each time, it was grinded for $10 \mathrm{~min}$ and sieved for $2 \mathrm{~min}$ to obtain the desired particle size of 75 micron. After grinding and sieving it was again weighed. Weight of the waste left after sieving was $66 \mathrm{~g}$. Weight of the sieved clay produced with desired size of 75 micron was $234 \mathrm{~g}$.

\subsection{Clay Dispersion Procedure}

Clay dispersion was produced in water. Clay dispersion in water produced using the percentage concentration of $2,4,6$, 8 , and 10 . The selected weights of clay $2 \mathrm{~g}, 4 \mathrm{~g}, 6 \mathrm{~g}, 8 \mathrm{~g}$, and 10 were separately placed in $100 \mathrm{ml}$ measuring cylinder. The amount of water added to make $100 \mathrm{ml}$ using jet bottle; where the clay in measuring cylinder was continuous shaking manually. Once water was leveled to $100 \mathrm{ml}$, the shaking was continued for 1 minute.

Subsequently, each measuring cylinder was observed for clay settling immediately, and after 2 minutes, 4 minutes, and 24 hours.

\subsection{Fabric Finishing Procedure}

Each fabric specimen (sized length $200 \mathrm{~mm} \pm 2 \mathrm{~mm}$ and width $80 \mathrm{~mm} \pm 2 \mathrm{~mm}$ ) was nip padded in clay dispersion. The clay dispersion produced in measuring cylinder at the selected clay loading was continuously shaking manually for 1 minute, and applied to fabric through nip padding. Each fabric specimen was padded at squeezing pressure of $0.1 \mathrm{bar}$, dried in oven at $60^{\circ} \mathrm{C}$ for $5-10$ minutes. The fabric pick up is shown in respective tables.

\subsection{Evaluation of Flame Retardancy}

Vertical flame retardant test using standard BS EN ISO 6940 2004. Bottom edge ignition at $30^{\circ}$ was used. However, the finished fabrics were tested at ambient conditions, without standard conditioning. Each reported value of T1 (ease ignition time), T2 (half- length burning time), and T3 (full- length burning time) was mean of at least three measurements. Size of finished specimen tested was $200 \mathrm{~mm}$ $\times 80 \mathrm{~mm}$.

\section{Results and discussion}

\subsection{Stability of Clay Dispersion}

Stability of clay dispersion in water was performed using clay 4 . The concentration studies were $2 \%, 4 \%, 6 \%, 8 \%$ and $10 \%$. For this purpose clay 4 loadings of $2 \mathrm{~g}, 4 \mathrm{~g}, 6 \mathrm{~g}, 8 \mathrm{~g}$ and $10 \mathrm{~g}$ in $100 \mathrm{ml}$ measuring cylinders were dispersed. Each measuring cylinder was shaking manually for 1 minute, and the pictures were taken to observe the settling of clay immediately following 1 minute (Figure $3 \mathrm{a}$ ), then following 2 minutes (Figure 3b), 4 minutes (Figure 3c), and finally these were observed after 24 hours (Figure $3 \mathrm{~d}$ ).

The immediate dispersion of clay, and those observed after 2 or 4 minutes were apparently similar. However, after 24 hours all the dispersed clay was settled to bottom cylinder (Figure 3d). An immediate aqueous dispersion of clay was appropriate to apply to fabric resulting in a relatively homogenous distribution of clay particles to fiber surface. 


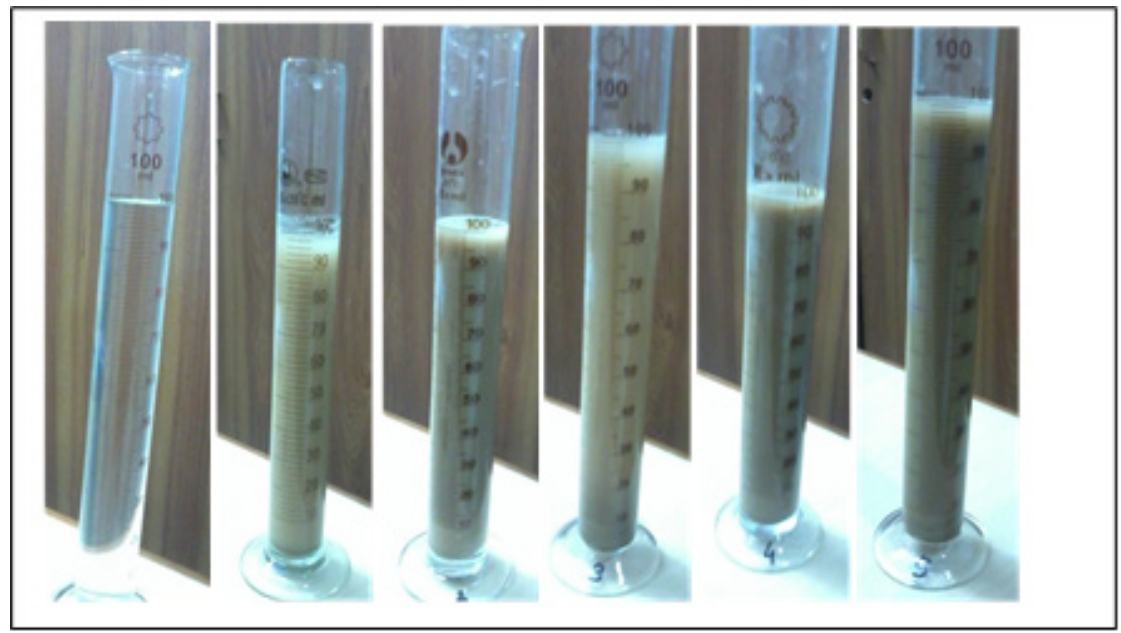

Figure 3a. Pictures taken immediately after dispersing the clay in measuring cylinders (from left to right): Plain Water, $2 \%, 4 \%, 6 \%, 8 \%$ and $10 \%$ loading of clay.

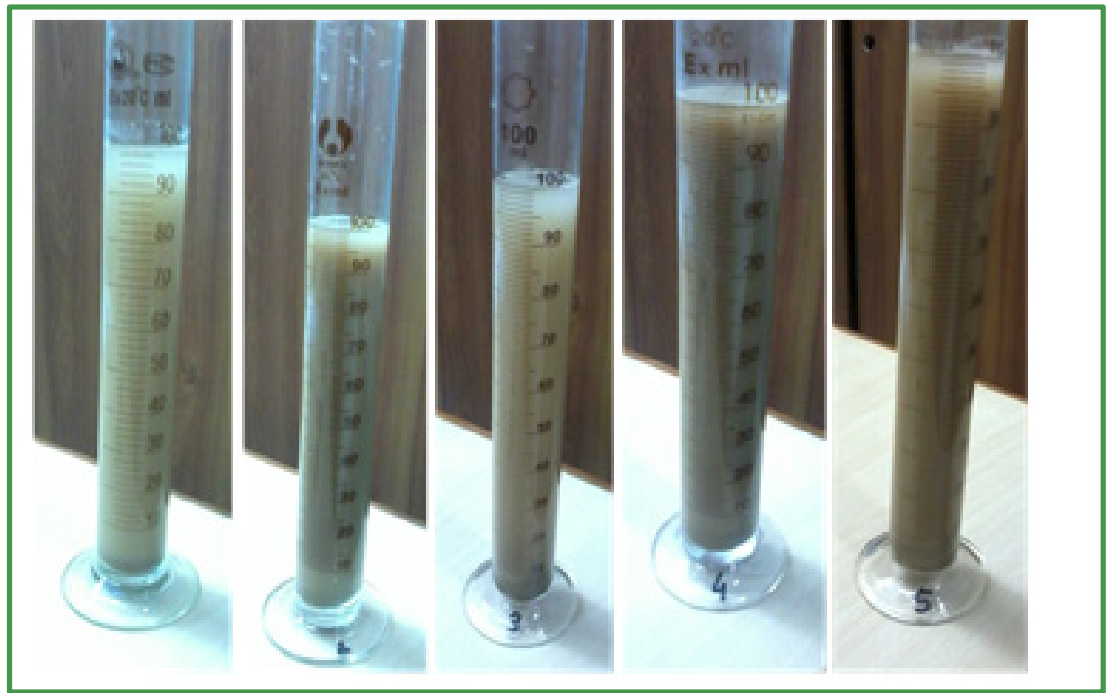

Figure 3b. Pictures taken 2 minutes after dispersing the clay in measuring cylinders (from left to right): $2 \%, 4 \%, 6 \%, 8 \%$ and $10 \%$ loading of clay.

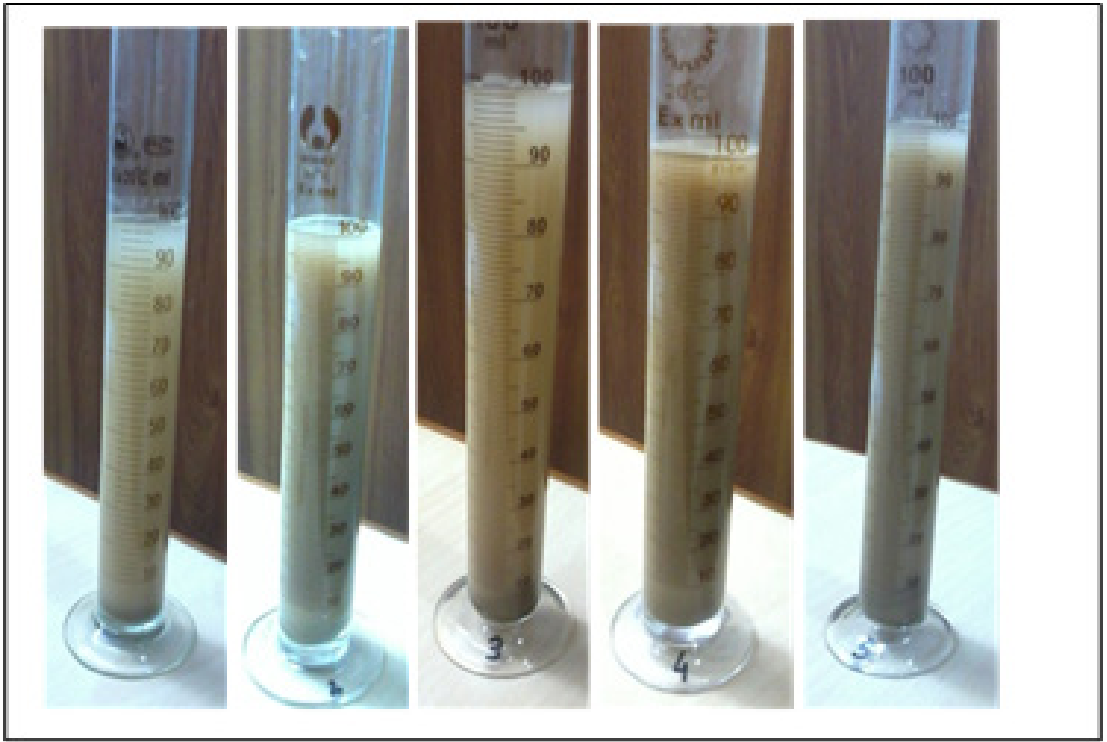

Figure 3c. Pictures taken 4 minutes after dispersing the clay in measuring cylinders (from left to right): $2 \%, 4 \%, 6 \%, 8 \%$ and $10 \%$ loading of clay. 


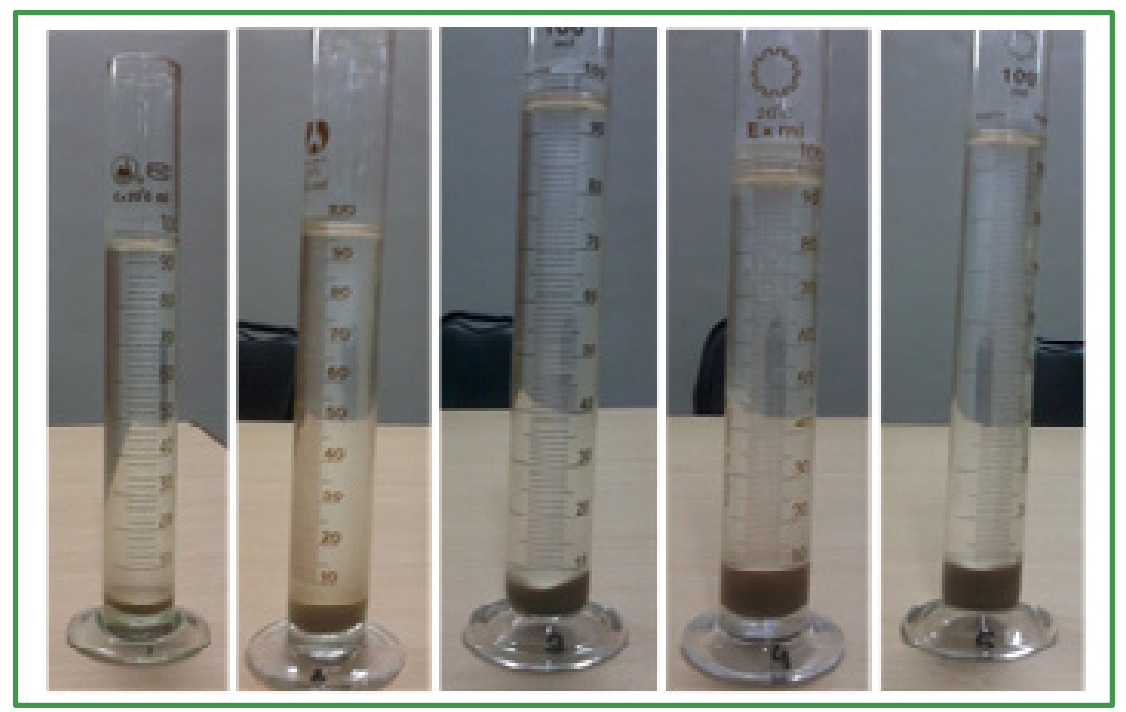

Figure 3d. Pictures taken 24 hours after dispersing the clay in measuring cylinders (from left to right): $2 \%, 4 \%, 6 \%, 8 \%$ and $10 \%$ loading of clay.

\subsection{Fabric Finishing}

The bleached cotton fabric padded in aqueous clay dispersion, and various percentage add- on are shown in Table 1. At any particular clay loading, the amount of clay add- on was similar. Smallest clay add- on was achieved with $2 \%$ loading that was $2.16 \%$; and the highest was achievable with $10 \%$ clay loading that was $13.7 \%$.

Table 1. Clay add- on in the finished using clay- 4.

\begin{tabular}{|c|c|c|c|c|c|}
\hline S No & Dry Fabric Wt (g) & Wet Fabric Wt (g) & Pick Up \% & Oven Dried Wt (g) & Add on \%age \\
\hline \multicolumn{6}{|c|}{$2 \%$ Clay- 4} \\
\hline S\#1 & 7.2 & 15 & 108.3 & 7.5 & 2.16 \\
\hline $\mathrm{S} \# 2$ & 7 & 14.6 & 108.6 & 7.6 & 2.17 \\
\hline $\mathrm{S} \# 3$ & 7 & 14.6 & 108.6 & 7.2 & 2.17 \\
\hline \multicolumn{6}{|c|}{$4 \%$ Clay- 4} \\
\hline $\mathrm{S} \# 4$ & 7 & 14.6 & 108.6 & 7.4 & 4.34 \\
\hline $\mathrm{S} \# 5$ & 6.8 & 14.2 & 108.8 & 7.2 & 4.35 \\
\hline $\mathrm{S} \# 6$ & 7.2 & 15.2 & 111.1 & 7.6 & 4.44 \\
\hline \multicolumn{6}{|c|}{$6 \%$ Clay- 4} \\
\hline S\#7 & 6.6 & 14.4 & 118 & 7 & 7.08 \\
\hline $\mathrm{S} \# 8$ & 7 & 15.4 & 120 & 7.2 & 7.2 \\
\hline $\mathrm{S} \# 9$ & 68 & 14.6 & 114.7 & 7 & 6.88 \\
\hline \multicolumn{6}{|c|}{$8 \%$ Clay- 4} \\
\hline S\#14 & 6.8 & 13.98 & 105 & 7.6 & 8.44 \\
\hline $\mathrm{S} \# 15$ & 7 & 15.5 & 121 & 7.7 & 9.68 \\
\hline S\#16 & 7.1 & 15.56 & 119 & 8.1 & 9.52 \\
\hline \multicolumn{6}{|c|}{$10 \%$ Clay- 4} \\
\hline S\#11 & 7 & 16.5 & 137 & 8.28 & 13.7 \\
\hline $\mathrm{S} \# 12$ & 6.8 & 14.9 & 119 & 8.01 & 11.9 \\
\hline S\#13 & 7 & 15.4 & 120 & 7.9 & 12 \\
\hline
\end{tabular}

Results obtained for padding the fabrics in clay- 3 at loading of $2 \%-10 \%$ are shown in Table 2 . Similar levels of clay- 3 add- on were achieved in the finished fabrics. The smallest add- on was $2.08 \%$ obtained using clay loading of $2 \%$, and the maximum was $11.29 \%$ achieved at clay loading of $10 \%$. Compared to clay- 4 , maximum clay add- on obtained with clay- 3 was smaller. However, it was attributed to an increased pick-up observed with clay- 4 at $10 \%$ loading. 
Table 2. Clay add- on in the finished using clay- 3 .

\begin{tabular}{|c|c|c|c|c|c|}
\hline S No & Dry Fabric Wt (g) & Wet Fabric Wt (g) & Pick Up \% & Oven Dryed Wt (g) & Add on \%age \\
\hline \multicolumn{6}{|c|}{$2 \%$ Clay 3} \\
\hline S\#17 & 6.6 & 13.47 & 104 & 6.96 & 2.08 \\
\hline $\mathrm{S} \# 18$ & 7 & 14.42 & 106 & 7.28 & 2.12 \\
\hline S\#19 & 6.3 & 13.2 & 109 & 6.66 & 2.18 \\
\hline \multicolumn{6}{|c|}{$4 \%$ Clay 3} \\
\hline $\mathrm{S} \# 20$ & 6.3 & 13.03 & 106 & 6.82 & 4.24 \\
\hline $\mathrm{S} \# 21$ & 6.3 & 13.14 & 108 & 6.76 & 4.32 \\
\hline $\mathrm{S} \# 22$ & 6.3 & 13.11 & 108 & 6.77 & 4.32 \\
\hline \multicolumn{6}{|c|}{$6 \%$ Clay 3} \\
\hline $\mathrm{S} \# 23$ & 6.3 & 12.9 & 104 & 6.81 & 6.24 \\
\hline $\mathrm{S} \# 24$ & 6.1 & 12.66 & 107 & 6.57 & 6.42 \\
\hline $\mathrm{S} \# 25$ & 6.3 & 13.05 & 107.1 & 6.77 & 6.42 \\
\hline \multicolumn{6}{|c|}{$8 \%$ Clay 3} \\
\hline $\mathrm{S} \# 26$ & 6.3 & 13.08 & 107.6 & 6.9 & 8.60 \\
\hline $\mathrm{S} \# 27$ & 6.5 & 13.36 & 105.5 & 7.07 & 8.44 \\
\hline $\mathrm{S} \# 28$ & 6.4 & 13.08 & 104 & 6.94 & 8.32 \\
\hline \multicolumn{6}{|c|}{$10 \%$ Clay 3} \\
\hline $\mathrm{S} \# 29$ & 6.3 & 13.23 & 110 & 6.97 & 11 \\
\hline $\mathrm{S} \# 30$ & 6.2 & 13.2 & 112 & 6.88 & 11.29 \\
\hline $\mathrm{S} \# 31$ & 6.4 & 13.53 & 111.4 & 7.07 & 11.14 \\
\hline
\end{tabular}

\subsection{Effect of Shade on Finished Fabric}

An important visual observation was the difference seen as change in color in the finished fabric relative to bleached fabric. The fabric finished with clay-4 showed slight change in color; however those finished with clay- 3 showed significantly golden yellow shade.

The fabric padded in clay- 4 , at loading from $2 \%$ to $6 \%$ significantly retained the whiteness similar to unfinished bleached fabric. However, at clay- 4 loading of $8 \%-10 \%$ the color of the finished fabric was dusty. All the finished fabric using clay- 3 with any concentration showed golden yellow shade that was lighter at $2 \%$ loading and stronger at $10 \%$ loading.

\subsection{Flame Retardancy}

\subsubsection{Burning time}

The fabrics finished with clay- 4 , and the control bleached fabric were evaluated for ease of ignition ( $\mathrm{T}$ 1), half- length burning (T 2), and full- length burning (T 3). The results are shown in Table 3.

Importantly, all the finished clay fabrics showed an enhancement in flame retardancy relative to bleached unfinished fabric. There was reduction in the ease of ignition ( $\mathrm{T}$ 1), i.e. taking an increased time in producing selfsustained flame. The time taken in half- length burning (T 2) and full- length burning ( $\left.\begin{array}{ll}\mathrm{T} & 3\end{array}\right)$ of finished fabrics was increased.

The $\mathrm{T} 1$ value was continued to improve with clay- 4 loading of $2 \%$, and $4 \%$, and further enhancement in clay- 4 loading to $6 \%-8 \%$ showed no significant change. However, reduction in the speed of flame propagation was observed with any increasing clay- 4 concentration from $2 \%-10 \%$.

The T 2 and T 3 values were gradually continue to increase with any loading of clay- 4 from $2 \%-10 \%$ relative to bleached unfinished fabric. The improvement was significant in T 3 that increased $(21.38 \%)$ from 18.47 to 22.42 seconds with clay- 4 loading of $2 \%$; and finally increased (46.99 \%) to 27.15 seconds with loading of $10 \%$.

Summarized results showing the various values of $\mathrm{T} 1, \mathrm{~T} 2$, and $\mathrm{T} 3$ for finished fabrics using clay- 4 can be seen in Figure 4.

Results obtained in assessing the flame retardancy of fabrics finished using clay- 3 are shown in Table 3 . The finished fabrics, relative to those finished using clay- 4 , showed more significant increase in the time taken for ignition, an increased value of $\mathrm{T} 1$. The $\mathrm{T} 1$ values observed for bleached unfinished, $2 \%$ clay- 4 finished, and $2 \%$ clay- 3 finished fabrics were 0.30 seconds, 0.45 seconds, and 0.68 seconds respectively. The reduction in the ease of ignition ( $\mathrm{T}$ 1) obtained using $2 \%$ clay-3 loading was more significant, relative to bleached cotton, that was $126.66 \%$. 
Table 3. Flame retardant performance of fabrics finished with clay- 4 .

\begin{tabular}{|c|c|c|c|c|c|}
\hline $\mathrm{S} \#$ & T1 (Seconds) & T2 (Seconds) & T3 (Seconds) & Flame propagation & Residue \\
\hline \multicolumn{6}{|c|}{ Bleached } \\
\hline 1 & 0.27 & 10.9 & 18.55 & Rapid Fire & Ash \\
\hline 2 & 0.35 & 11.11 & 18.21 & Rapid Fire & Ash \\
\hline 3 & 0.28 & 10.87 & 18.65 & Rapid Fire & Ash \\
\hline Mean & 0.30 & 10.96 & 18.47 & & \\
\hline \multicolumn{6}{|c|}{$2 \%$ Clay- 4} \\
\hline 7 & 0.49 & 12.86 & 22.99 & Reduced fire speed & Ash \\
\hline 8 & 0.45 & 12.27 & 22.8 & Reduced fire speed & Ash \\
\hline 9 & 0.43 & 12.40 & 21.49 & Reduced fire speed & Ash \\
\hline Mean & 0.45 & 12.51 & 22.42 & & \\
\hline \multicolumn{6}{|c|}{$4 \%$ Clay- 4} \\
\hline 10 & 0.49 & 12.14 & 22.65 & Reduced fire speed & Ash, Char \\
\hline 11 & 0.56 & 11.93 & 24.84 & Reduced fire speed & Ash, Char \\
\hline 12 & 0.84 & 12.92 & 24.33 & Reduced fire speed & Ash, Char \\
\hline Mean & 0.63 & 12.33 & 23.94 & & \\
\hline \multicolumn{6}{|c|}{$6 \%$ Clay- 4} \\
\hline 13 & 0.57 & 12.77 & 24.52 & Slow fire spread & Ash, Char \\
\hline 14 & 0.65 & 13.80 & 25.52 & Slow fire spread & Ash, Char \\
\hline 15 & 0.69 & 13.65 & 25.62 & Slow fire spread & Ash, Char \\
\hline Mean & 0.64 & 13.40 & 25.22 & & \\
\hline \multicolumn{6}{|c|}{$8 \%$ Clay- 4} \\
\hline 16 & 0.68 & 12.86 & 26.64 & Slow fire spread & Char \\
\hline 17 & 0.74 & 13.65 & 27.32 & Slow fire spread & Char \\
\hline 18 & 0.61 & 13.98 & 26.03 & Slow fire spread & Char \\
\hline Mean & 0.67 & 13.49 & 26.66 & & \\
\hline \multicolumn{6}{|c|}{$10 \%$ Clay- 4} \\
\hline 19 & 0.90 & 13.67 & 27.64 & Slow fire spread & Char \\
\hline 20 & 0.75 & 13.49 & 27.43 & Slow fire spread & Char \\
\hline 21 & 0.85 & 13.68 & 26.39 & Slow fire spread & Char \\
\hline Mean & 0.83 & 13.61 & 27.15 & & \\
\hline
\end{tabular}

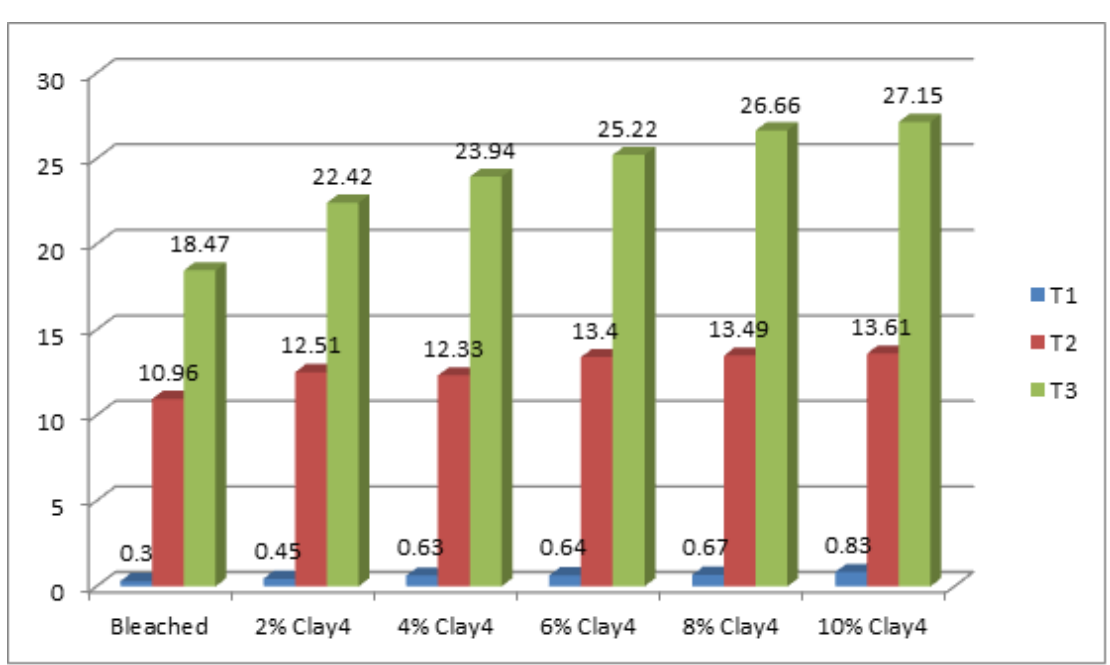

Figure 4. The various values of $\mathrm{T} 1, \mathrm{~T} 2$, and $\mathrm{T} 3$ for fabrics finished using clay- 4 .

The tendency of clay- 3 to offer increased values of $\mathrm{T} 1$, relative to clay- 4 , was observable at any concentration used. The probable reason may be the finer particle size, and particle size distribution. The T 1 value using clay- 3 was gradually continue to enhance, and reached to 1.10 seconds at the maximum clay- 3 loading of $10 \%$. It was $24.54 \%$ higher than the value obtained with clay- 4 at the same loading of $10 \%$. However, similar to clay- 4 , increasing the concentration of clay- 3 from $2 \%$ to $6 \%$, the slight increase in the values of T 2 and $\mathrm{T} 3$ was observed.

Interestingly, time taken in full- length burning ( $\mathrm{T}$ 3) by the fabric finished using clay- 3 was generally similar to that 
obtained using clay- 4 . It was more similar at the increased concentrations $(6 \%$ - $10 \%)$ used.

Summarized results showing the various values of T 1, T 2, and T 3 for fabrics finished using clay- 3 are shown in Figure 5 .

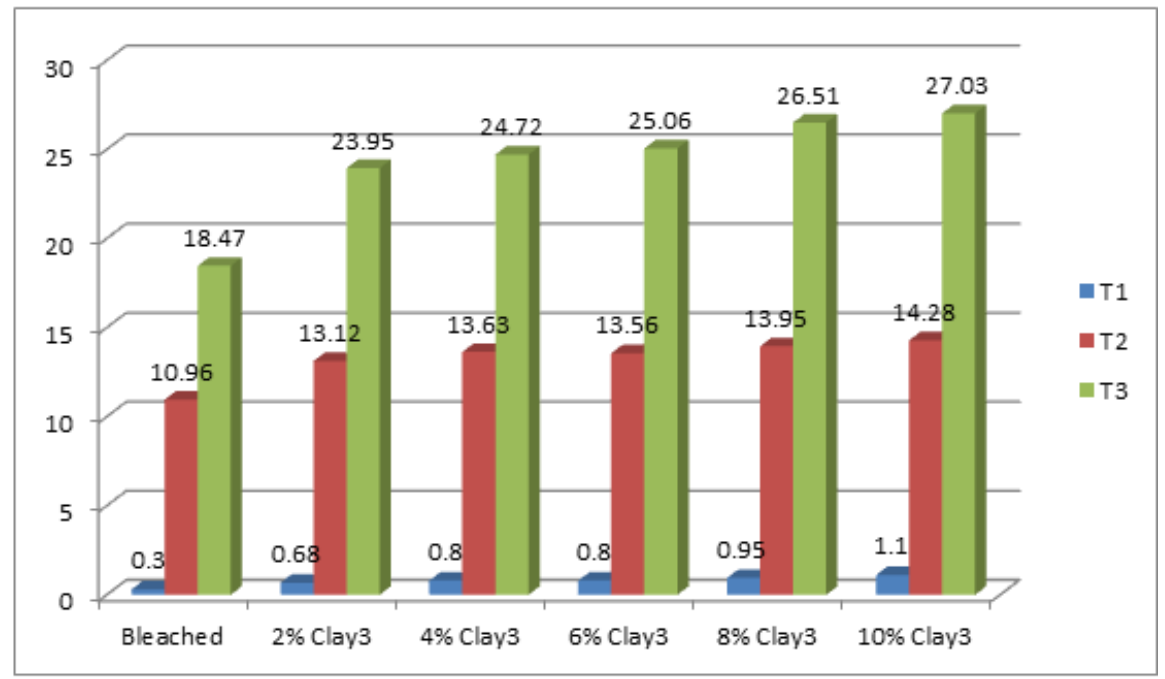

Figure 5. The various values of $\mathrm{T} 1, \mathrm{~T} 2$, and $\mathrm{T} 3$ for fabrics finished using clay- 3 .

Table 4. Flame retardant performance of fabrics finished with clay- 3.

\begin{tabular}{|c|c|c|c|c|c|}
\hline $\mathrm{S} \#$ & T1 (Seconds) & T2 (Seconds) & T3 (Seconds) & Flame propagation & Residue \\
\hline \multicolumn{6}{|c|}{ Bleached } \\
\hline 1 & 0.27 & 10.9 & 18.55 & Rapid Fire & Ash \\
\hline 2 & 0.35 & 11.11 & 18.21 & Rapid Fire & Ash \\
\hline 3 & 0.28 & 10.87 & 18.65 & Rapid Fire & Ash \\
\hline Mean & 0.30 & 10.96 & 18.47 & & \\
\hline \multicolumn{6}{|c|}{$2 \%$ Clay- 3} \\
\hline 28 & 0.59 & 13.46 & 24.56 & Reduced fire speed & Ash, Char \\
\hline 29 & 0.77 & 13.36 & 23.86 & Reduced fire speed & Ash, Char \\
\hline 30 & 0.68 & 12.59 & 23.45 & Reduced fire speed & Ash, Char \\
\hline Mean & 0.68 & 13.12 & 23.95 & & \\
\hline \multicolumn{6}{|c|}{$4 \%$ Clay- 3} \\
\hline 31 & 0.64 & 13.33 & 24.64 & Reduced fire speed & Char \\
\hline 32 & 0.80 & 13.83 & 24.74 & Reduced fire speed & Char \\
\hline 33 & 0.98 & 13.74 & 24.79 & Reduced fire speed & Char \\
\hline Mean & 0.80 & 13.63 & 24.72 & & \\
\hline \multicolumn{6}{|c|}{$6 \%$ Clay- 3} \\
\hline 34 & 0.81 & 14.40 & 24.67 & Slow fire spread & Char \\
\hline 35 & 0.75 & 12.93 & 24.95 & Slow fire spread & Char \\
\hline 36 & 0.86 & 13.37 & 25.56 & Slow fire spread & Char \\
\hline Mean & 0.80 & 13.56 & 25.06 & & \\
\hline \multicolumn{6}{|c|}{$8 \%$ Clay- 3} \\
\hline 37 & 0.98 & 13.77 & 26.93 & Slow fire spread & Char \\
\hline 38 & 0.99 & 13.49 & 26.11 & Slow fire spread & Char \\
\hline 39 & 0.90 & 14.61 & 26.51 & Slow fire spread & Char \\
\hline Mean & 0.95 & 13.95 & 26.51 & & \\
\hline \multicolumn{6}{|c|}{$10 \%$ Clay- 3} \\
\hline 40 & 0.99 & 14.85 & 26.93 & Slow fire spread & Char \\
\hline 41 & 1.03 & 13.77 & 26.65 & Slow fire spread & Char \\
\hline 42 & 1.30 & 14.23 & 27.51 & Slow fire spread & Char \\
\hline Mean & 1.10 & 14.28 & 27.03 & & \\
\hline
\end{tabular}




\subsubsection{Flame propagation}

An important effect noted evaluating the finished fabrics using any type the clay was the visual assessment of flame propagation. In bleached unfinished fabric the propagation of fire was fast; however, smaller concentration of $2 \%$ used for any of the clay type resulted in the reduction of fire growth. This effect was more significant with increasing the concentration from $2 \%$ to $10 \%$. At the clay loading of $6 \%$ $10 \%$, the reduction in the growth of fire was significantly observable.

\subsubsection{Residue of burnt fabric}

Following the full- length burning of all the fabrics, including bleached unfinished and clay finished fabrics, the residue was observed. The bleached unfinished fabric was burnt to ash. However, except with the fabrics finished using clay- 4 at $2 \%$ loading, the formation of residual char was observed in all the fabrics finished the two types of the clay used at any concentration. The amount of char produced was more significant in residue of fabrics finished using clay- 3 . The fabrics finished using clay- 3 at loading from $4 \%$ to $10 \%$ showed increasingly significant amount of char formation, where the fabrics finished using clay- 4 showed significant char formation at loading of $6 \%$ to $10 \%$. This again may be attributed to the probable finer particle size, and particle size distribution in case of clay 3 resulted in improved flame retardancy.

\section{Conclusions}

This study evaluated the flame retardancy produced by the two types of locally- available clays. The purpose was to obtain some useful results in enhancing the indigenous study of clay reserves of country in textile finishing. The results obtained may be useful in enhancing the development of low- cost flame retardant finish for fibrous material.

The obtained clay samples were evaluated for the ability to remain dispersed in aqueous finish bath, and the bleached cotton fabric was finished using clay- 3 and clay- 4 . The finished fabrics were assessed using the vertical flame retardant test BS EN ISO 69402004.

The time in seconds for ease of ignition (T 1), half- length burning and full- length burning was determined coupled with observation of flame propagation and the formation of reside (ash/ char).

It was found that the two types of clays used in this study can enhance the flame retardancy of finished fabric in terms of $\mathrm{T} 1, \mathrm{~T} 2$, and $\mathrm{T} 3$, and significant amount of char was obtainable with increasing clay concentration. However, the char formation was more significant in fabrics finished using clay- 3 relative to those finished using clay- 4 .

\section{Conflict of Interests}

The authors do not have financial and personal relationships that might bias the work or presenting this work as research paper. Moreover, mentioning any commercial product name or any company name (Guangzhou Hongjing Lab Equipment, and Dual Manufacturing Co etc.) implicitly or explicitly does not show any preference over those not mentioned. The work is reported as it was conducted as part of academic studies, and presented without any commercial interest or relationship ${ }^{1}$

\section{REFERENCES}

[1] Horrocks AR, Flame retardant finishing of textiles, Review of Progress in Coloration and Related Topics 1986, 6 (1) 62101.

[2] Kishore K, Mohandas K, Action of phosphorus compounds on fire- retardancy of cellulosic materials: a review, Fire and Materials 1982, 6 (2), 54- 58.

[3] Faheem Uddin, Concerns of brominated flame retardant, Industrial Fabric Bulletin 2003, 3, 55- 56.

[4] Roberts DL, Hall ME, Horrocks AR, Environmental aspects of flame retardant textiles- an overview, Review of Progress in Coloration and Related Topics 1992, 22 (1), 48- 57.

[5] Faheem Uddin, Advancement in nanotechnology of polymers and fibers, International Dyer, (March 2008) 33$35)$.

[6] Faheem Uddin, Clay, nanoclay and montmorillonite minerals. Metallurgical and Materials Transactions A: Volume 39, Number 12 / (December, 2008) 2804-2814).

[7] Eric Devaux, Maryline Rochery, Serge Bouebigot, Polyurethane/ clay and polyurethane/ POSS nanocomposites as flame retarded coating for polyester and cotton fabrics, Fire and Materials, Special Issue: Fire Behaviour of Textiles, Volume 26, Issue 4- 5 (July- October 2002) 149- 154.

[8] Sheng Zhang, A. Richard Horrocks, Richard Hull, Baljinder K. Kondola, Flammability, degradation and structural characterization of fiber- forming polypropylene containing nanoclay- flame retardant combinations, Polymer Degradation and Stability, Volume 91, Issue 4 (April 2006) 719- 725).

[9] Magensh D. Teli, Ravindra D. Kale, Polyester nanocomposite fibers with improved flame retardancy and thermal stability, Polymer Engineering and Science, Volume 52, Issue 5 (May 2012) 1148- 1154

[10] Jennifer Tata, Jenny Alorgi, Alberto Frache, Optimization of the procedure to burn textile fabrics by cone calorimeter: Part II. Results on nanoparticle- finished polyester, Fire and Materials, Volume 36, (2012) 527- 536.

[11] Yu- Chin Li, Jessica Schulz, Sarah Mannen, Chris Delhom, Brian Condon, Sechin Chang, Mauro Zammarano, Jaime C. Grunlan, Flame retardant behavior of polyelectrolyte- clay

1 Paper presented at The 4th International Conference on Textile and Clothing, March 28- 30, 2013, organized by University of Management and Technology, Lahore, in collaboration with Textile Institute Manchester (TI) UK (Pakistan Chapter) and Society for Dyers and Colorists (SDC) UK (Pakistan Chapter). 
thin film assemblies on cotton fabric, ACS Nano, 4, 6 (2010) 3325- 3337 .

[12] Leslie A White, Preparation and thermal analysis of cottonclay nanocomposite, Journal of Applied Polymer Science, Volume 92, (2004) 2125.
[13] Kadhiravan Shanmuganathan, Sarang Deodhar, Nicholas A. Dembsey, Qinguo Fan, Prabir K Patra, Condensed- phase flame retardation in nylon 6- layered silicate nanocomposites: Films, fibers, and fabrics, Polymer Engineering and Science, Volume 48, Issue 4 (April 2008) 662- 675. 